\title{
Fiber-Optic Temperature Sensor Using a Spectrum-Modulating Semiconductor Etalon
}

Glenn Beheim

Lewis Research Center

Cleveland, Ohio

Klaus Fritsch

John Carroll University

Cleveland, Ohio

and

Donald J. Anthan

Cleveland State University

Cleveland, Ohio

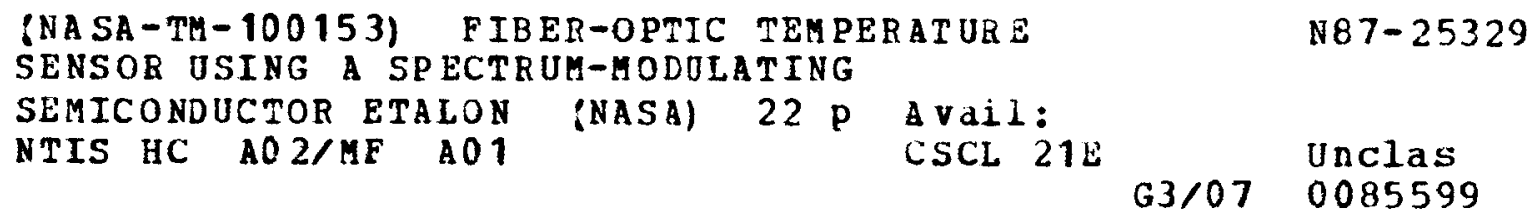

N $87-25329$

Unclas G3/07 0085599

\section{Prepared for}

O-E/Fibers '87, A Symposium on Fiber Optics and Integrated Optoelectronics sponsored by SPIE-The International Society for Optical Engineering San Diego, California, August 16-21, 1987

\section{N/SA}


FIBER-OPTIC TEMPERATURE SENSOR USING A SPECTRUM-MODULATING SEMICONDUCTOR ETALON

\author{
Glenn Beheim \\ National Aeronautics and Space Administration \\ Lewis Research Center \\ Cleveland, Ohio 44135 \\ Klaus Fritsch \\ Department of Physics \\ John Carroll University \\ Cleveland, Ohio 44118 \\ Donald J. Anthan \\ Department of Engineering Technology \\ Cleveland state University \\ Cleveland, Ohio 44115
}

\title{
ABSTRACT
}

This paper describes a fiber-optic temperature sensor that uses a spectrum-modulating sic etalon. The spectral output of this type of sensor may be analyzed to obtain a tem$\stackrel{f}{a}$ perature measurement which is largely independent of the transmission properties of the $\hat{m}$ sensor's fiber-optic link. A highly precise laboratory-type spectrometer is described in $\omega$ detail, and this instrument is used to study the properties of this type of sensor. Also described are a number of different spectrum analyzers that are suitable for use in a practical thermometer.

\section{INTRODUCTION}

Spectrum-modulation methods have been widely used in an effort to develop highly stable types of fiber-optic sensors. A Fabry-Perot interferometer is one type of spectrummodulating transducer that can be used to sense a number of different physical parameters.1-9 An interferometer's spectral transfer function, as a function of wavenumber $k$, contains a number of periodically spaced minima and maxima the positions of which are determined by the interferometer's optical path difference (OPD). A Fabry-Perot type sensor must incorporate some mechanism which causes the interferometer's OPD to be a stable and sensitive function of only the parameter to be measured. If the sensor is illuminated by a broadband source, then the positions of the maxima and minima in the sensor's output spectrum can be used to determine the magnitude of the sensed parameter. The information content of this type of spectrally encoded signal is unlikely to be degraded by routine variations in the transmission properties of the fiber link. Besides providing a high degree of link-independence, Fabry-Perot type sensors can be compact and rugged, and they can provide both high sensitivity and high stability.

This paper describes a temperature sensor which uses a reflective silicon-carbide (Sic) etalon. The etalon's OPD is temperature dependent due, primarily, to the variation with temperature of its refractive index. The sensing etalon is illuminated by spectrally broadband light from a light-emitting diode (LED). The sensed temperature can then be determined from the positions of the minima in the sensor's output spectrum. A number of different techniques may be used to analyze this spectrum in order to obtain a temperature measurement. In this paper, a highly precise laboratory-type instrument is used to examine the properties of this type of sensor. Several simpler types of spectrum analyzers, more suitable for use in a practical thermometer, are also described.

\section{SIC-ETALON TEMPERATURE SENSOR}

Figure 1 shows, schematically, a fiber-optic temperature sensor that uses a reflective sic etalon. The remotely located sensor is linked to the optical source and detection electronics by multimode optical fibers. Separate input and output fibers are used to eliminate the optical offsets that would occur in a single-fiber link due to reflections from within the $f i b e r$ connectors. A light-emitting diode (LED) serves as a source of spectrally broadband light. The light from the LED is transmitted by an input fiber to a fused-fiber type of 2:1 coupler $\mathrm{C}_{S}$. A high-temperature input/output fiber directs the light from the coupler to the sensing etalon. The light reflected by the sensing etalon travels back through the input/output $f$ iber and coupler to the sensor's output fiber. The 
output fiber transmits the spectrally-encoded signal to the optical spectrum analyzer. A microprocessor then uses the results of the spectral analysis to calculate the sensed temperature.

The temperature-sensing etalon is a single-crystal film of cubic sic that has a thickness of approximately $7.7 \mu \mathrm{m}$. The $\mathrm{SiC}$ film is grown by chemical vapor deposition on a $400 \mu \mathrm{m}$ thick silicon substrate. 10 The reflectivities of the etalon's surfaces are determined by the Fresnel formulae. At $825 \mathrm{~nm}$, the refractive indices of $\mathrm{SiC}$ and $\mathrm{Si}$ are approximately $2.61 \mathrm{Il}$ and $3.67 \mathrm{i}$; therefore, the reflectivities, $R_{1}$ and $R_{2}$, of the etalon's front and rear surfaces are estimated to be 0.20 and 0.03 , respectively. As shown in Fig. l, a small ceramic ferrule is used to align the fiber end and the sic crystal, and the sensor assembly is bonded together using a high-temperature cement (Sauereisen No. 31 ).

The upper trace of Fig. 2 shows the spectrum of the LED source, while the lower two traces show the sensor's output spectra at temperatures $\mathrm{T}$ of 20 and $260{ }^{\circ} \mathrm{C}$. The sensor's spectral reflectance is a minimum at each of the etalon's resonant wavenumbers, $2 \pi m / n_{S} \mathscr{L}_{S}$. where $m$ is an integer, $n_{S}$ is the etalon's refractive index and $\mathscr{L}_{S}$ is twice the etalon's thickness (here, $n_{S}=2.61$ and $\mathscr{L}_{S}=15.4 \mu \mathrm{m}$ ). As the etalon's temperature is increased, ns increases and therefore the resonant wavenumbers decrease, causing the minima in the sensors' output spectrum to shift to longer wavelengths.

\section{INTERFEROMETRIC SPECTRUM ANALYZER}

One method of analyzing the sensor's output spectrum uses a tunable interferometer. $1,5,6,9$ This approach requires that the sensing etalon's opD, nS $\mathscr{L}_{\mathrm{S}}$, be considerably greater than the optical source's coherence length, $\mathscr{L}_{\mathrm{C}}$. Also, the spectrum analyzing interferometer's OPD, $\mathscr{L}_{A}$, must be nearly equal to $\mathrm{n}_{\mathrm{S}} \mathscr{L}_{\mathrm{S}}$ (specifically, $\left|\mathrm{n}_{\mathrm{S}} \mathscr{L}_{\mathrm{S}}-\mathscr{L}_{\mathrm{A}}\right| \leqslant \mathscr{L}_{\mathrm{C}}$ ). In this case, no interference will result if either interferometer is interrogated separately. However, the series arrangement of interferometers produces fringes of superposition, the phase of which is proportional to $\mathrm{n}_{\mathrm{S}} \mathscr{L}_{\mathrm{S}}-\mathscr{L}_{\mathrm{A}}$.

In this paper, a tranmissive Michelson interferometer is used to analyze the output of the reflective sensing etalon. The analysis here follows that of Ref. 6 . The optical system is assumed to be lossless, aside from a four-fold intensity reduction that results from twice traversing the coupler $C_{S}$. The source is assumed to have unity intensity and a Gaussian spectral distribution $i_{i}(k)$ that is symmetric about wavenumber $k_{0}$ :

$$
i_{i}(k)=\frac{1}{\sqrt{\pi} \sigma} \exp \left[-\left(\frac{k-k_{0}}{\sigma}\right)^{2}\right]
$$

Provided both interferometers are nondispersive, the instrument's output has an intensity that is given by

$$
\mathrm{I}_{\mathrm{f}}=\mathrm{A}_{0}-\mathrm{A}_{1} \mathrm{~V}\left(\mathrm{n}_{\mathrm{S}} \mathscr{L}_{\mathrm{S}}-\mathscr{L}_{\mathrm{A}}\right) \cos \left[\mathrm{k}_{0}\left(\mathrm{n}_{\mathrm{S}} \mathscr{L}_{\mathrm{S}}-\mathscr{L}_{\mathrm{A}}\right)\right]
$$

where,

$$
\begin{aligned}
& A_{0}=\frac{1}{8}\left[1-\frac{\left(1-R_{1}\right)\left(1-R_{2}\right)}{1-R_{1} R_{2}}\right] \\
& A_{1}=\frac{1}{8} \frac{\left(1-R_{1}\right)\left(1-R_{2}\right)}{1-R_{1} R_{2}} \sqrt{R_{1} R_{2}} \\
& V(x)=\exp \left[-\left(\frac{\sigma x}{2}\right)^{2}\right]
\end{aligned}
$$

Here, $V$ is the source's degree of coherence, and $R_{1}$ and $R_{2}$ are the reflectivities of the etalon's surfaces. The fringe visibility $n$ is equal to (A $\left./ A_{0}\right) \mathrm{V}\left(\mathrm{n}_{\mathrm{S}} \mathscr{L}_{\mathrm{S}}-\mathscr{L}_{\mathrm{A}}\right)$ and is a maximum for $\mathscr{L}_{\mathrm{A}}=\mathrm{n}_{\mathrm{S}} \mathscr{L}_{\mathrm{S}}$. For $\mathrm{R}_{1}$ and $\mathrm{R}_{2}$ equal to 0.20 and 0.03 , the maximum fringe visibility is 0.27 . The sensing etalon's phase shift, relative to the phase of the analyzer, is $\theta_{\mathrm{S}}=\mathrm{k}_{0}\left(\mathrm{n}_{\mathrm{S}} \mathscr{L}_{\mathrm{S}}-\mathscr{L}_{\mathrm{A}}\right)$. Equation (2) has the same form as the expression for 
the output of a two-beam interferometer, if ( $n_{S} \mathscr{L}_{\mathrm{S}}-\mathscr{L}_{\mathrm{A}}$ ) in Eq. (2) is replaced by the single interferometer's OPD. Therefore, $\theta_{S}$ can be determined by using phase-measurement techniques that have been developed for simple two-beam interferometers.

For a SiC etalon, the material's optical dispersion is appreciable, and Eq. (2) is no longer applicable. The visibility of the fringes of superposition depends on the degree of coincidence between the resonant wavenumbers of the two interferometers. For the nondispersive analyzer, adjacent resonant wavenumbers are separated by $\Delta \mathrm{k}_{\mathrm{A}}=2 \pi / \mathscr{L}_{\mathrm{A}}$. For the dispersive sensing etalon, $\Delta \mathrm{k}_{\mathrm{S}}=2 \pi / \mathrm{n}_{\mathrm{S}} \mathscr{L}_{\mathrm{S}}$, where $\mathrm{n}_{\mathrm{S}}=\mathrm{n}_{\mathrm{S}}+\mathrm{kdn} \mathrm{n}_{\mathrm{S}} / \mathrm{dk}$. Therefore, the fringes of superposition can be expected to have maximum visibility at $\mathscr{L}_{\mathrm{A}}=\mathrm{n}_{\mathrm{S}} \mathscr{L}_{\mathrm{S}}$. Because, at $825 \mathrm{~nm}, \mathrm{n}_{\mathrm{S}}=2.609$ and $\mathrm{n}_{\mathrm{S}}=2.698$, the etalon's optical dispersion is expected to significantly increase the value of $\mathscr{L}_{A}$ which maximizes the fringe visibility. To determine the effect of the sensing etalon's dispersion, the system's output intensity, as a function of $\mathscr{L}_{\mathrm{A}}, \mathscr{L}_{\mathrm{S}}$, and $\mathrm{n}_{\mathrm{S}}$ was numerically calculated. 6 The calculation used a Gaussian fit to the LED spectrum of Fig. 2 and an extrapolation of the refractive index data of Ref. 11. The following equation was found to be a good approximation for the instrument described in this paper:

$$
\mathrm{I}_{\mathrm{f}}=\mathrm{A}_{0}-\mathrm{A}_{1} \mathrm{~V}\left(\mathrm{n}_{\mathrm{S}} \mathscr{L}_{\mathrm{S}}-\mathscr{L}_{\mathrm{A}}\right) \cos \left[\mathrm{k}_{0}\left(\mathrm{n}_{\mathrm{S}} \mathscr{L}_{\mathrm{S}}-\mathscr{L}_{\mathrm{A}}\right)+\Phi_{\mathrm{S}}\right]
$$

Here $A_{0}, A_{1}$, and $V$ are defined as before, $n_{S}$ and $n_{S}$ are calculated at wavenumber $k_{0}$, and $\Phi_{S}$ is a phase offset. The sensing etalon's phase shift is in this case given by $\theta_{\mathrm{S}}=\mathrm{k}_{0}\left(\mathrm{n}_{\mathrm{S}} \mathscr{L}_{\mathrm{S}}-\mathscr{L}_{\mathrm{A}}\right)+\Phi_{\mathrm{S}}$.

Figure 3 shows, as functions of $\mathscr{L}_{A}$, the measured fringe visibility $n$ for the case of a series arrangement of sensing etalon and analyzer as well as for the case of the analyzer alone. The optical source is the LED whose spectrum is shown in Fig. 2 . The series arrangement of matched-OPD interferometers attains its maximum fringe visibility, of 0.15 at $\mathscr{L}_{\mathrm{A}}=42 \mathrm{\mu m}$. This result was used in Eq. (6) to estimate $\mathscr{L}_{\mathrm{S}}$. At $\mathscr{L}_{\mathrm{A}}=\mathrm{n}_{\mathrm{S}} \mathscr{L}_{\mathrm{S}}$, the fringes due solely to the analyzer cavity have an amplitude which is 0.3 percent of the amplitude of the fringes of superposition. Therefore, the assumptions made in the preceding analysis regarding the LED's coherence function are justified.

\section{INSTRUMENT DESCRIPTION}

Figure 4 shows, schematically, a thermometer that uses a tunable bulk-optic interferometer to analyze the sensor's output spectrum. Light from the pigtailed LED (MA/Com Laser Diode Labs No. IRE-160FA) is transmitted through the Michelson interferometer and then injected into one arm of a fused-fiber coupler $C_{A}$. The analyzer's opD is modulated by applying a sinusoidal voltage to a piezoelectric mirror translator or PzT (Physik Instrument No. P-286). The analyzer's time-varying OPD is $\mathscr{L}_{\mathrm{AO}}+B s i n(w t)$. Coupler C directs half the analyzer's output through the sensor's input fiber and coupler CS to the sensing etalon. The reflected light travels through coupler $C_{S}$ and the output fiber to photodiode $\mathrm{PD}_{\mathrm{S}}$. The optical fibers are step-index with a $100 \mu \mathrm{m}$ core diameter and a 0.3 N.A. Although separate input and output fibers are used here, this instrument is unaffected by dc offsets and can therefore be used with a bidirectional single-fiber 1 ink. 5,6

The output of $\mathrm{PD}_{\mathrm{S}}$ is analyzed by a phase-measurement circuit (PMC) to obtain $\theta_{\mathrm{S}}$. The phase-measurement method has been described previously.13,14 The PMC is shown in the top part of $\mathrm{Fig}$. 5. It consists of the following components connected in series: an ac amplifier, an analog switch, a frequency-tracking bandpass filter, and a phasemeter. The analog switch gates the amplified $\mathrm{PD}_{\mathrm{S}}$ signal at frequency $\omega$. The switch's synchronization signal is time delayed so that the switching transients occur at the zero-crossings of $\cos (2 \omega t)$. A commercial tracking filter (EG \& G No. 5204/97) with a 20 Hz bandwidth is used to extract the gated signal's component at frequency $2 \omega$. The filtered signal's phase, with respect to $\cos (2 \omega t)$, is measured using a commercial phasemeter (EG \& G No. 5204/95) to directly obtain $\theta_{\mathrm{S}}$.

For the PMC to operate correctly, $B$ must be adjusted so that the bandpass filter's output has an amplitude which is independent of $\theta_{S}$ (this occurs for $\mathrm{k}_{0} \beta=2.8 \mathrm{rad}$ ). Also, the fringe visibility must remain constant as $\mathscr{L}_{A}$ varies between $\mathscr{L}_{\text {AO }}-B^{B}$ and $\mathscr{L}_{\mathrm{A} 0}+B$. This requirement is most nearly satisfied for $\mathscr{L}_{\mathrm{AO}} \approx$ nS $\mathscr{L}_{\mathrm{S}}$, where the LED's
degree of coherence $\mathrm{V}$ varies slowly as a function of $\mathscr{L}_{\mathrm{A}}$, as shown in Fig. 3 .

To maintain a stable relationship between $\Theta_{\mathrm{S}}$ and the sensed temperature, both k0 and $\mathscr{L}_{\mathrm{A} 0}$ must be stabilized. The analyzer's mean OPD, $\mathscr{L}_{\mathrm{A} 0}$, is actively controlled using a length control circuit (LCC). The LCC tunes the PZT's bias voltage in order to fix $\mathscr{L}_{\mathrm{AO}}$ with respect to the OPD, $\mathrm{n}_{\mathrm{R}} \dot{L}_{\mathrm{R}}$, of a reference etalon. The reference etalon is mounted together with the LED on a temperature-controlled heatsink so that both $k_{0}$ and $n_{R} \mathscr{L}_{R}$ are held constant. As shown in Fig. 4, coupler $C_{A}$ directs half the analyzer's output 
through a GRIN lens collimator onto the reference etalon. The reflected light is then directed by $C_{R}$ onto photodiode $\mathrm{PD}_{\mathrm{R}_{\dot{\mathscr{S}}}}$ The reference and sensing etalon have nearly identical thicknesses so that $\mathrm{n}_{\mathrm{R}} \mathscr{L}_{\mathrm{R}} \approx \mathrm{n}_{\mathrm{S}} \dot{\mathscr{L}}_{\mathrm{S}}$.

The LCC uses the signal from PDR to derive the PZT's bias voltage. The LCC is shown in the bottom part of Fig. 5. It consists of the following components connected in series: an ac amplifier, a demodulator, and an integrator. The IC demodulator (Analog Devices No. AD630) multiplies the amplified $\mathrm{PD}_{\mathrm{R}}$ signal by sign (sin(wt)) to obtain a phasedifference signal. This signal is proportional to $\sin \left(\theta_{\mathrm{R}}\right)$ where $\theta_{\mathrm{R}}=\mathrm{k}_{0}\left(\mathrm{n}_{\mathrm{R}} \mathscr{L}_{\mathrm{R}}-\mathscr{L}_{\mathrm{AO}}\right)+$ $\Phi_{\mathrm{R}}$. The phase-difference signal is integrated and then applied to the PZT, thereby forcing the phase-difference signal to zero. The LCC tunes $\mathscr{L}_{\mathrm{A} 0}$ so that $\mathscr{L}_{\mathrm{A} 0}=\mathrm{n}_{\mathrm{R}} \mathscr{L}_{\mathrm{R}}+\Phi_{\mathrm{R}} / \mathrm{k}_{0}+$ $m \lambda_{0}$, where $m$ is an integer and $\lambda_{0}=2 \pi / \mathrm{k}_{0}$. The fringe order $m$ is determined by the initial value of $\mathscr{L}_{\text {A0 }}$ when the LCC is activated. Phase-measurement errors which arise due to the nonconstant fringe visibility make it necessary to give m the same value at each start-up. In the lab, prior to activating the LCC, the PDR signal is monitored on an oscilloscope and $\mathscr{L}_{\mathrm{A} 0}$ is adjusted with a micrometer in order to maximize the amplitude of the observed fringes. The LCC is then activated so that locking to the zeroth-order fringe is achieved.

\section{EXPERIMENTAL RESULTS}

Figure 6 shows the sensing etalon's phase shift $\theta_{\mathrm{S}}$ as a function of temperature, $T$, for temperatures ranging from 20 to $260^{\circ} \mathrm{C}$. The results of this calibration run are thereafter used to convert the measured values of $\Theta_{S}$ to a measured temperature value $T_{M}$. At $20{ }^{\circ} \mathrm{C}, \mathrm{d} \theta_{\mathrm{S}} / \mathrm{dT}=0.3 \mathrm{deg} /{ }^{\circ} \mathrm{C}$, therefore, $\mathrm{dn}_{\mathrm{S}} / \mathrm{d}_{\mathrm{T}} \approx 4.4 \times 10^{-5} /{ }^{\circ} \mathrm{C}$.

Because the sensing etalon is interrogated using noncollimated light, the measured value of $\theta_{S}$ may be expected to have some dependence on the light's modal distribution. Therefore, the influence of fiber bending on the instrument's output needed to be investigated. Figure 7 shows the effect of bending the sensor's input/output fiber near the splice with $C_{S}$. In normal use, changes in $\theta_{S}$ of several ${ }^{\circ} \mathrm{C}$ were observed due to bending of the input/output fiber. The fiber has a thin polyimide buffer and is inserted into a flexible fiberglass sleeve for protection. A stiffer, more heavily cabled hightemperature $f i b e r$ is required. Bends as small as $3 \mathrm{~cm}$ in diameter were placed in the cabled output arm of $C_{S}$ (near the splice with the high-temperature fiber) and changes in $\mathrm{T}_{\mathrm{M}}$ of as much as $2{ }^{\circ} \mathrm{C}$ were observed. The cabled fiber is sufficiently stiff, however, so that bends with this small a diameter are unlikely to occur in normal use. By heavily cabling the high-temperature fiber, the bending effects can probably be reduced to $\pm 0.5{ }^{\circ} \mathrm{C}$ or less.

Bends with diameters as small as $3 \mathrm{~cm}$ were also placed in the input fiber-optic cable, near the connection with $C_{S}$. The instrument's output was found to remain stable within $\pm 0.2{ }^{\circ} \mathrm{C}$. These results indicate that the coupler $\mathrm{C}_{S}$ may provide a beneficial mode-mixing effect. Therefore, using a mode scrambler near the end of the sensor's input/output fiber may significantly improve the instrument's stability. Use of lower N.A. fiber may also provide greater stability.

A considerable improvement in stability may be obtained by using a GRIN lens or miniature ball lens to collimate the light incident on the sensing etalon, as is done with the reference etalon used here. Figure 8 shows the small effect on $T_{M}$ that was produced by bending the reference etalon's input/output fiber.

The effect of reconnecting the sensor was determined by demating and then remating both of the $\mathrm{C}_{\mathrm{S}}$ connectors prior to each measurement of a fixed temperature. The connectors are a commonly used SMA type (OFTI No. 255). Figure 9 shows the results of 50 measurements at room temperature. The measured temperature $\mathrm{T}_{\mathrm{M}}$ had a standard deviation of $0.25{ }^{\circ} \mathrm{C}$. The optical signal incident on $\mathrm{PD}_{\mathrm{S}}$ underwent considerable intensity variations during this experiment; the relative standard deviation was 16 percent.

To investigate the cable effects, $20 \mathrm{~T}$ M measurements were performed. Prior to each odd-numbered measurement the two $10-\mathrm{m}$ long input and output cables were removed and the sensor was connected directly to $C_{A}$ and $\mathrm{PD}_{\mathrm{S}}$. Prior to each even-numbered measurement the cables were replaced. The resulting standard deviation of $\mathrm{T}_{\mathrm{M}}$ was $0.35{ }^{\circ} \mathrm{C}$.

Figure 10 shows the effect of locking the analyzer/reference-etalon combination to a different fringe order $\mathrm{m}$. These results show the analyzer must be locked to the same fringe order at each start-up if the sensor's calibration is to be maintained. Here, the zeroth-order fringe was located manually. A more practical instrument will require an automated locking procedure which incorporates some means of discriminating between fringe orders.1, 15 


\section{ALTERNATE SPECTRUM ANALYZERS}

A number of different types of spectrum analyzers are probably better suited for use in a practical instrument than the laboratory-type device described here. Figure ll shows an all-single-mode fiber implementation of the Michelson type of analyzer interferometer. This device may also be implemented using integrated-optics. To provide low cost and ease of use, multimode fibers may still be used to link the sensor with the analyzer. A single analyzer of this type may be used to power several sensors.

Figure 12 shows a spectrum analyzer which uses a passive sic etalon. The analyzer etalon is maintained at a constant temperature. The reflected and transmitted signals are detected by photodiodes $\mathrm{PD}_{\mathrm{R}}$ and $\mathrm{PD}_{\mathrm{S}}$, respectively. The two photodiode signals will vary in a complementary manner as the sensed temperature is changed. Therefore, the ratio of these two signals may be used to obtain a temperature-indicating signal which is independent of the fiber link's transmissivity.

Another promising approach is to use a micro-optic spectrometer as shown in Fig. 13 . This spectrometer uses a GRIN lens and a prism/grating assembly to disperse the spectrum across the elements of a linear photodiode array. An important advantage of this device is its potentially low cost, which is a result of using wavelength-division multiplexing (WDM) components that have been developed for use in fiber-optic communications systems.16 Another significant advantage of this approach is its convenience for use in sensor networks; a single spectrometer of this type may be used to analyze the outputs of a number of different sensors which can include wavelength multiplexed digital encoders as well as different kinds of Fabry-Perot-type sensors.2,17 A further advantage is the large amount of spectral information that is obtained. This information may be used, for example, to compensate changes in the LED's spectrum, making active temperature control unnecessary.

\section{CONCLUSION}

A spectrum-modulating temperature sensor which uses a SiC etalon has been described. A laboratory-type of spectrum analyzer for use with this sensor has been described in detail. This type of sensor has been shown to be potentially quite stable. Several types of spectrum analyzers suitable for use in practical thermometers have also been described.

\section{REFERENCES}

1. G. Beheim, K. Fritsch, and R.N. Poorman, "Fiber-Linked Interferometric Pressure Sensor," Rev. Sci. Instrum. (1987) to be published.

2. G. Beheim and K. Fritsch, "Spectrum-Modulating Fiber-optic Sensors for Aircraft Control Systems," NASA TM-88968 (1987).

3. K.L. Belsley, D.R. Huber, and J. Goodman, "All-Passive Fiber-optic Pressure Sensor," InTech 33(12), 39-42 (1986).

4. E.W. Saaski, et al, "A Family of Fiber Optic Sensors Using Cavity Resonator Microshifts," in Proceedings of the Fourth International Conference on Optical Fiber Sensors, pp. 11-14, Institute of Electronics and Communications Engineers of Japan, Tokyo, 1986.

5. G. Beheim, "Fibre-optic Thermometer Using Semiconductor-Etalon Sensor," Electron. Lett. 22(5), 238-239(1986).

6. G. Beheim, "Remote Displacement Measurement Using a Passive Interferometer with a Fiber Optic Link," Appl. Opt. 24(15), 2335-2340 (1985).

7. W.H. Quick, K.A. James, and J.E. Coker, "Fibre Optics Sensing Techniques," in First International Conference on Optical Fibre Sensors, pp. 6-9, IEE CP-221, IEE, London, 1983.

8. E.R. Cox and B.E. Jones, "Fibre Optic Color Sensors Based on Fabry-Perot Interferometry," in First International Conference on Optical Fibre Sensors, pp. 122-126, IEE CP-221, IEE, London, 1983.

9. D.A. Christensen, "Temperature Measurement Using Optical Etalons," Annual Meeting of Optical Society of America, Houston, TX, Oct. 1974.

10. J.A. Powell, L.G. Matus, and M.A. Kuczmarski, "Growth and Characterization of Cubic SiC Single-Crystal Films on Si," J. Electrochem. Soc. 134(6), pp. 1558-1565 (1987).

11. J.A. Powell, "Refractive Index and Birefringence of $2 \mathrm{H}$ Silicon Carbide," J. Opt. Soc. Am., 62(3), 34l-344, (1972). 
12. E.D. Palik, ed. Handbook of Optical Constants of Solids, pp. 547-569, Academic Press, Orlando (1985).

13. A.C. Lewin, A.D. Kersey, and D.A. Jackson, "Two Wide-Dynamic-Range Signal-Recovery Schemes for the Fibre-optic Gyroscope," IEE Proc. Pt. J, 132(5), 271-276 (1985).

14. B.Y. Kim and H.J. Shaw, "Phase-Reading, All-Fiber-Optic Gyroscope," Opt. Lett. 9(8), $378-380(1984)$.

15. G. Beheim, "Fiber Optic Interferometer Using Frequency-Modulated Laser Diodes," Appl. Opt. 25(19), 3469-3472 (1986).

16. K. Kobayashi and M. Seki, "Microoptic Grating Multiplexers and optical Isolators for Fiber Optic Communications," IEEE. J. Quantum Electron., 16(1), 11-22 (1980).

17. K. Fritsch and G. Beheim, "Wavelength-Division Multiplexed Digital Optical Position Transducer," Opt. Lett. $11(1), 1-3$ (1986). 


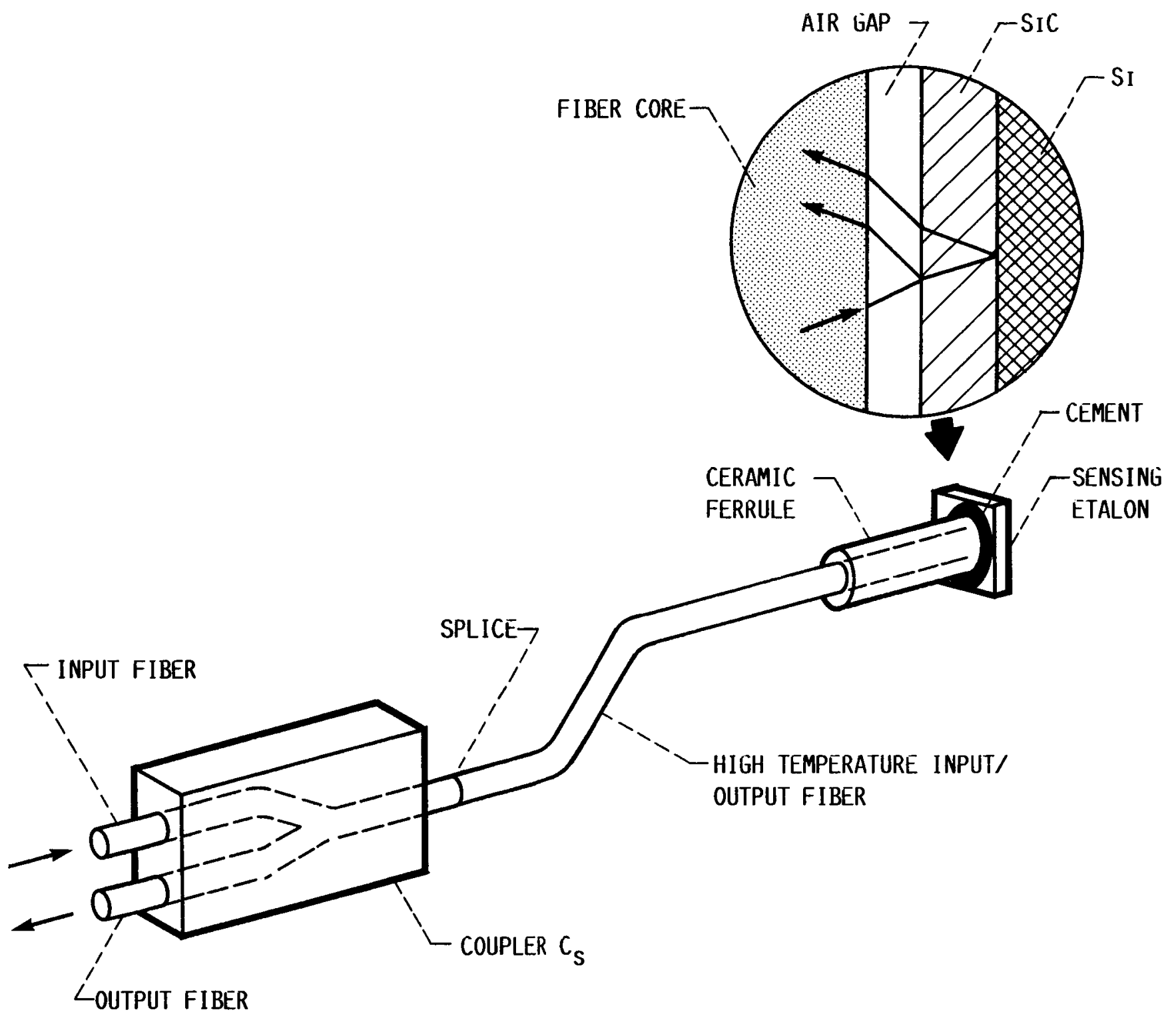

FIGURE 1. - SiC-ETALON TEMPERATURE SENSOR. 


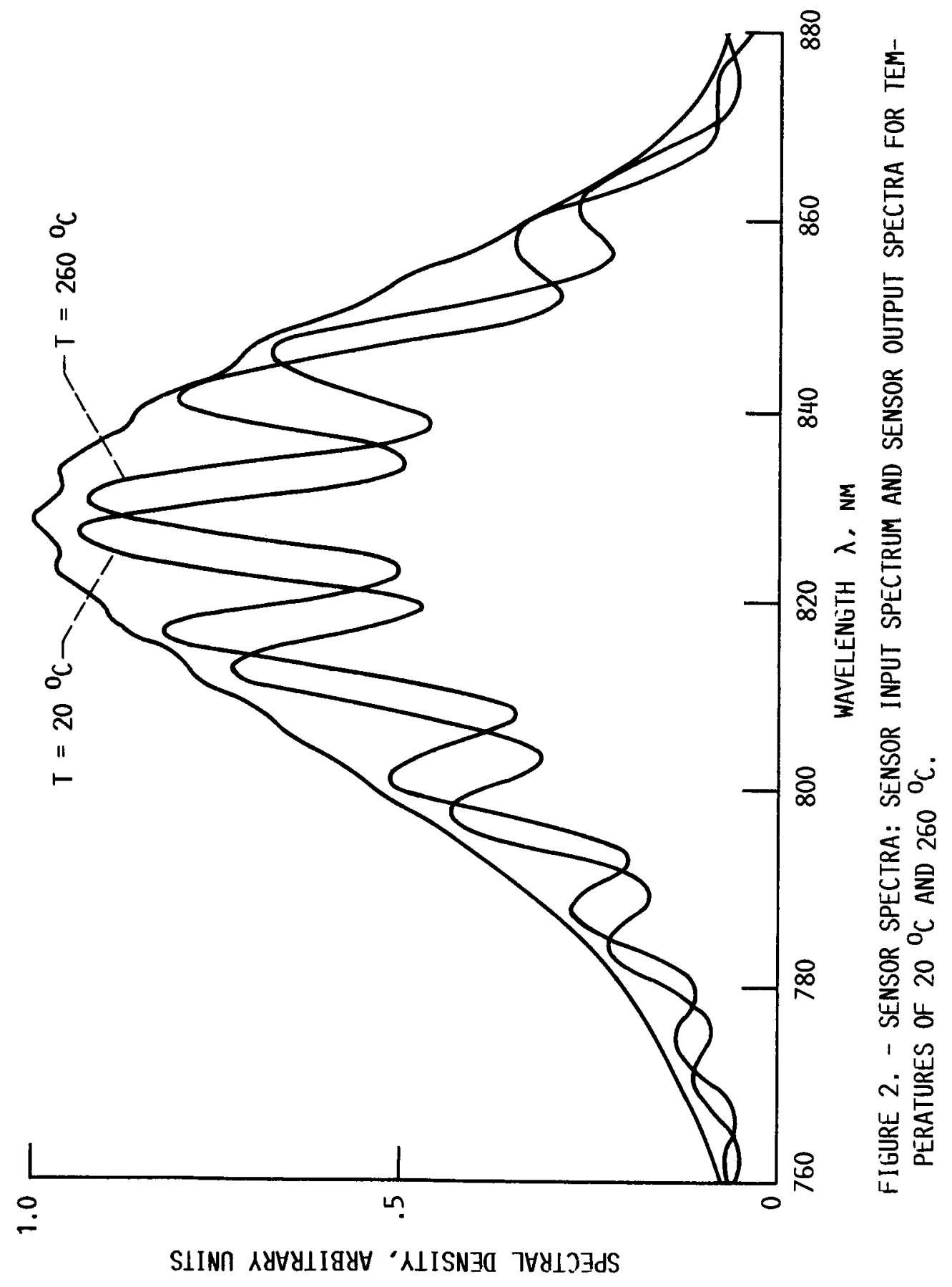




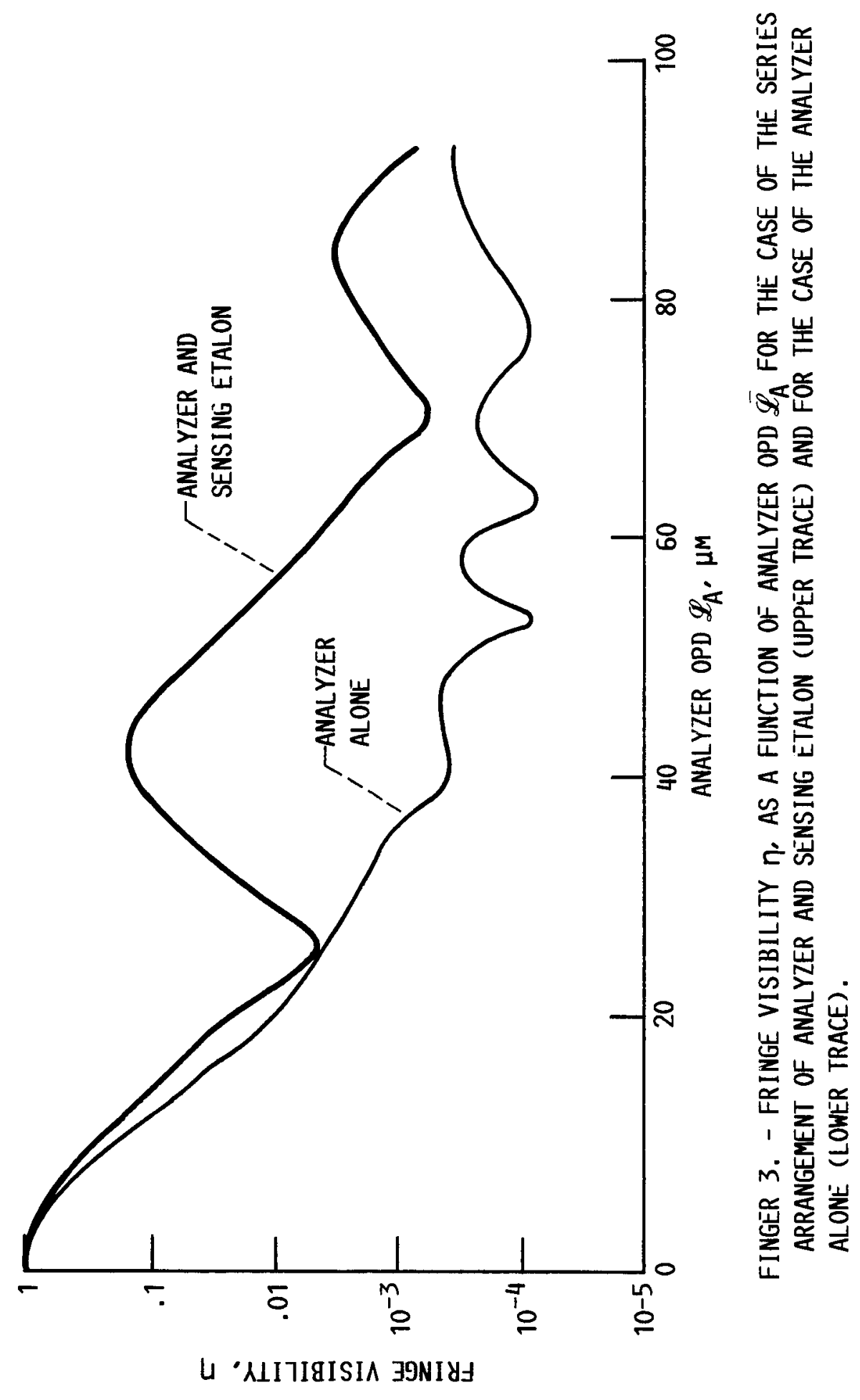




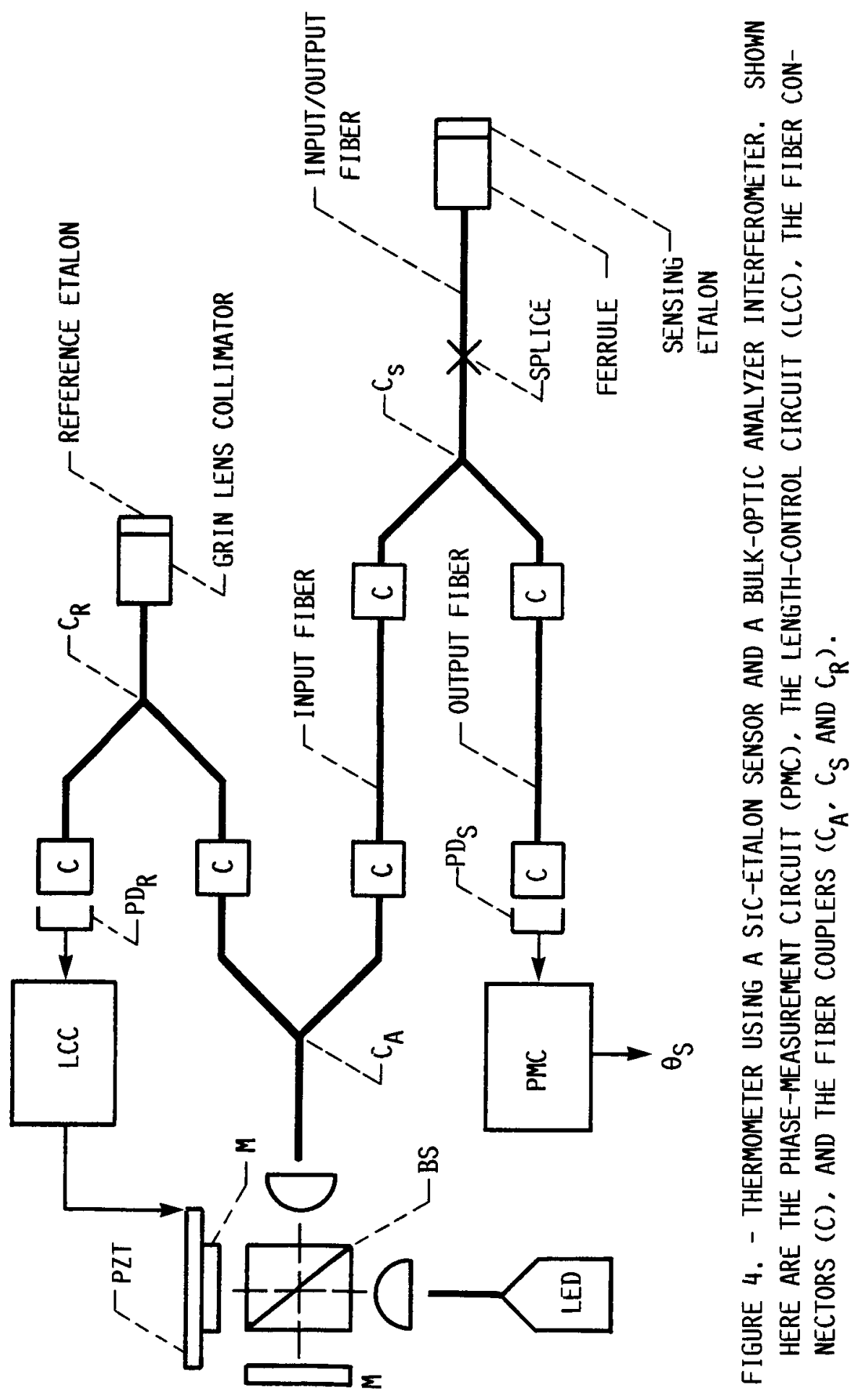




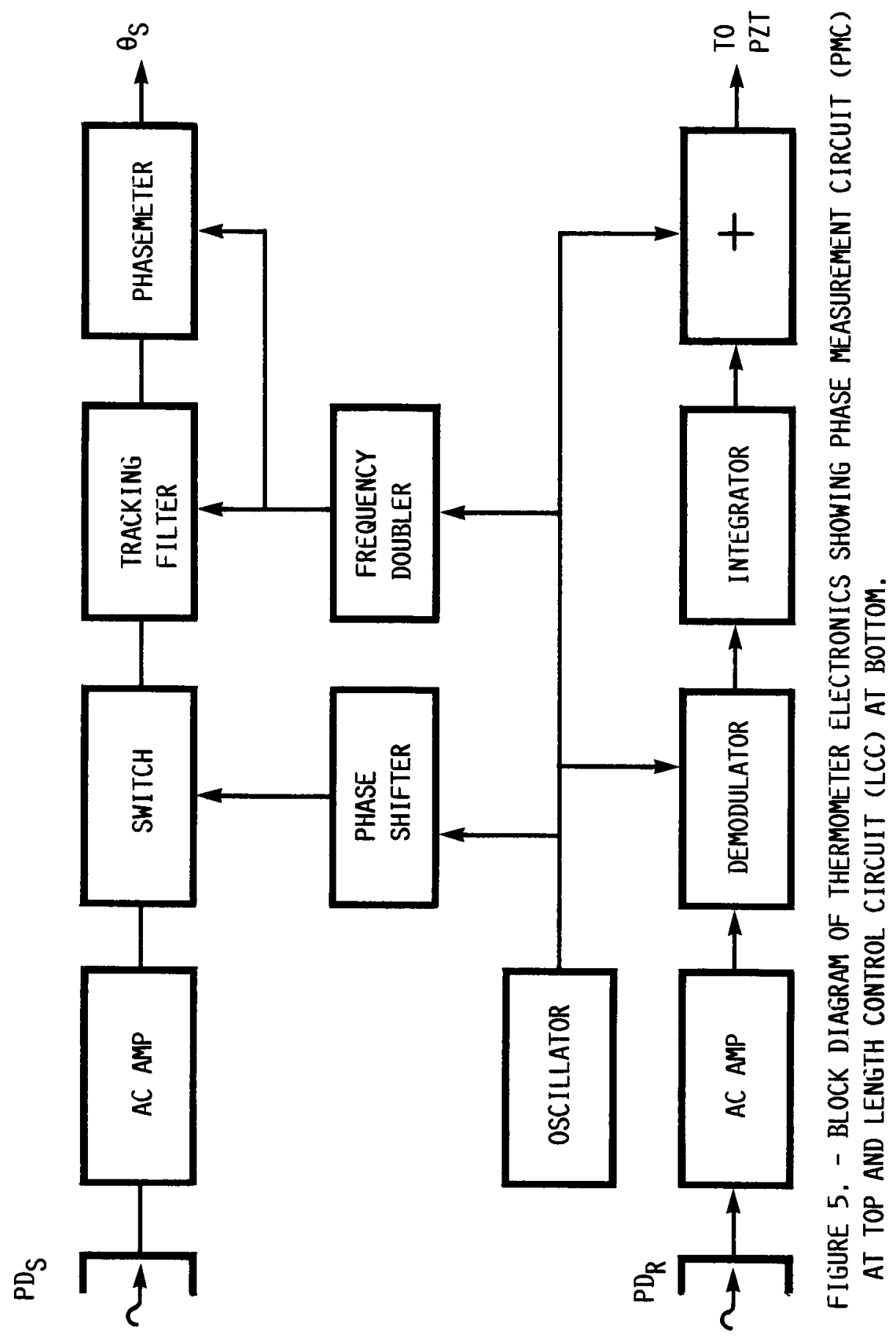




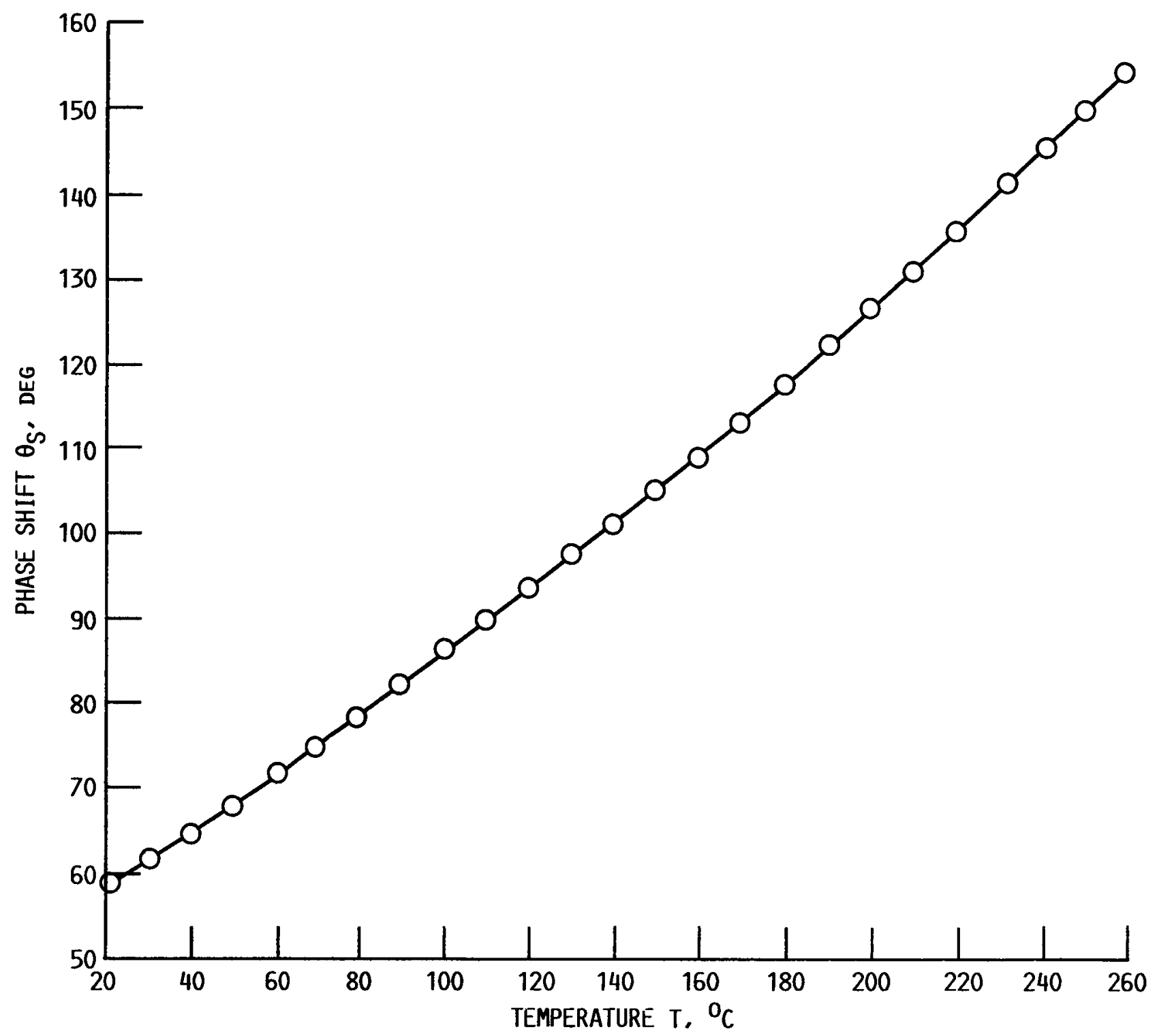

FIGURE 6. - THE SENSING ETALON'S PHASE SHIFT $\theta_{S}$ AS A FUNCTION OF TEMPERATURE T. 


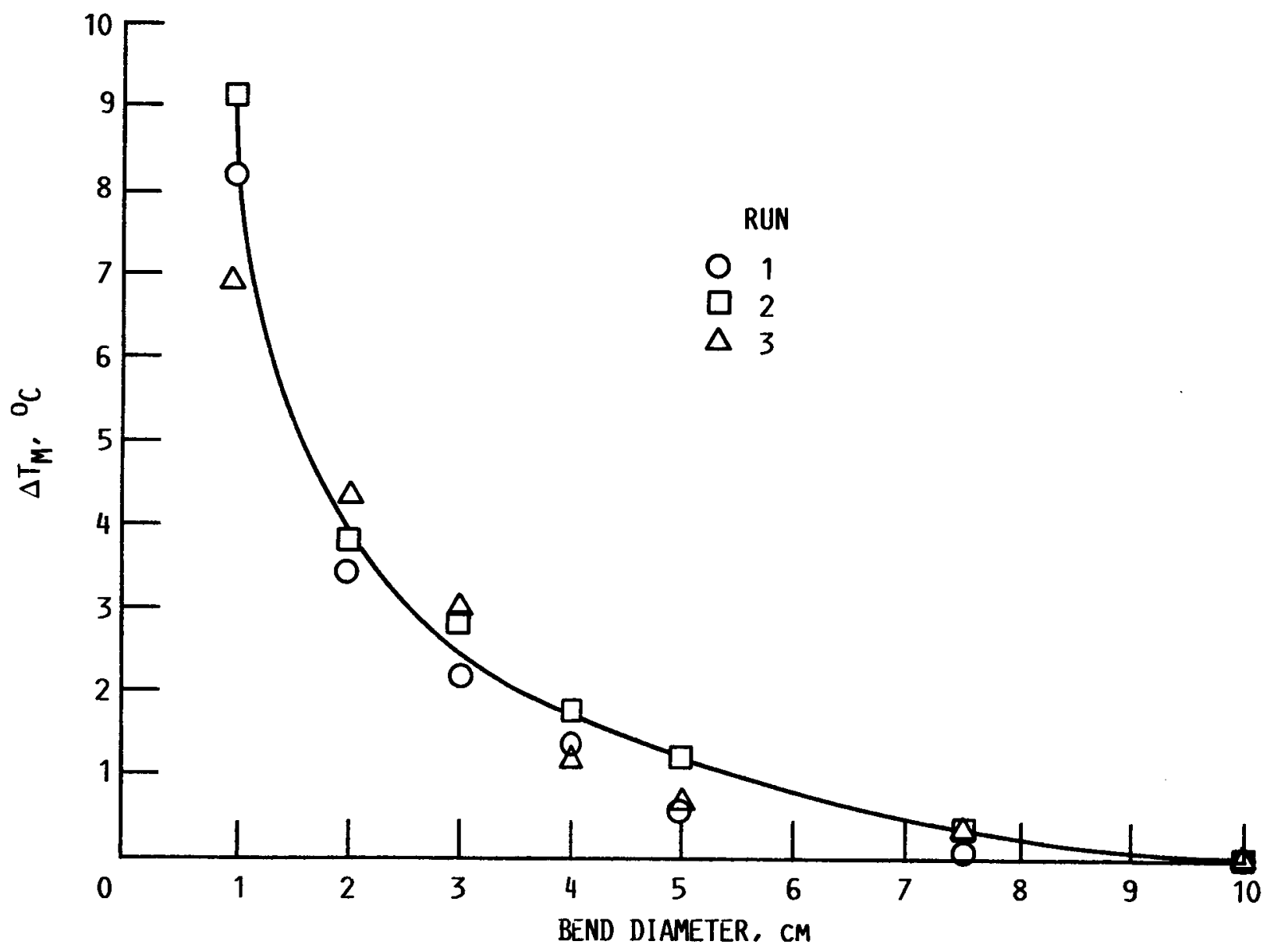

FIGURE 7. - EFFECT ON T $M$ OF BENDING THE SENSOR'S INPUT/OUTPUT FIBER. 


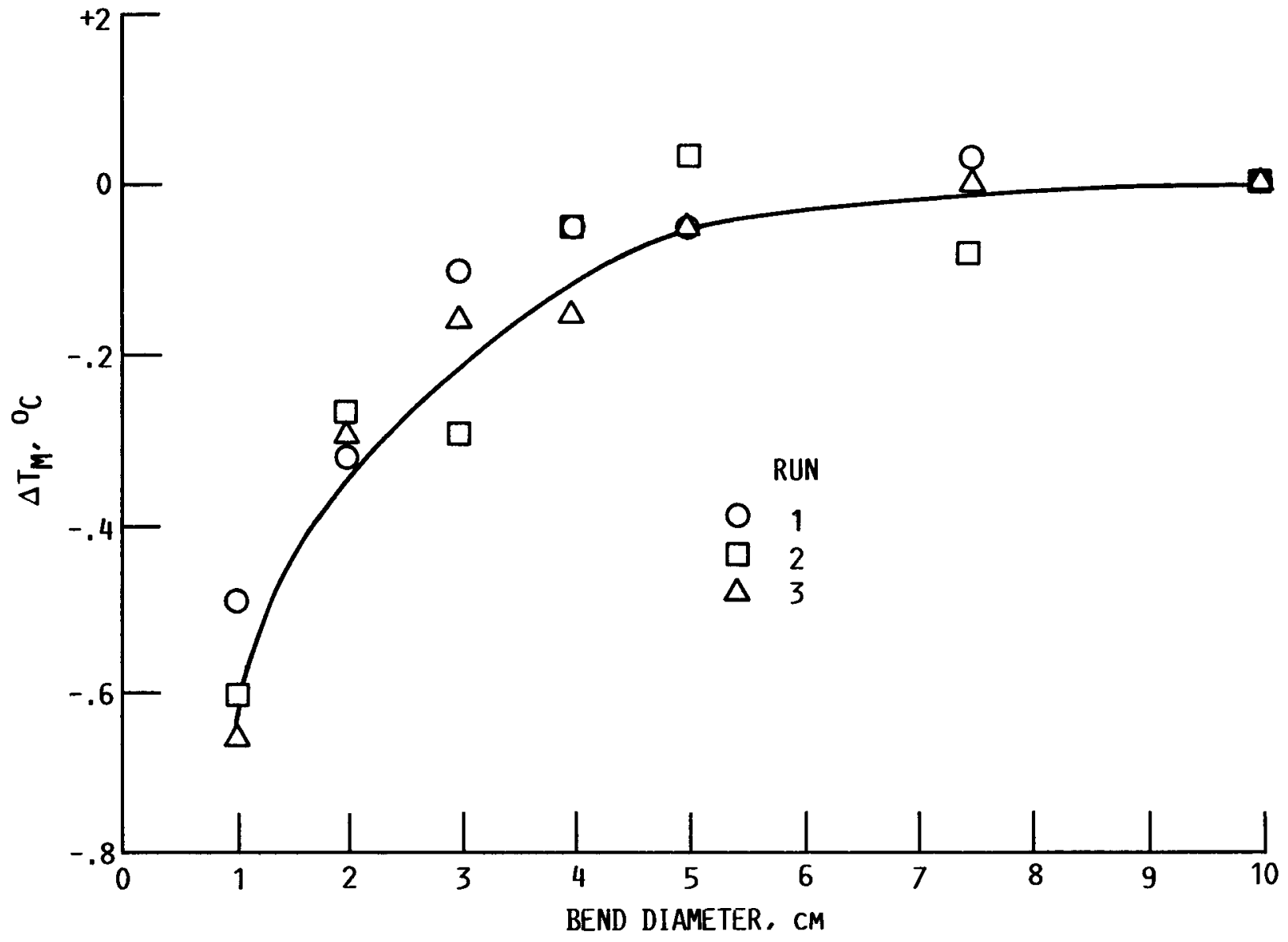

FIGURE 8. - EFFECT ON $T_{M}$ OF BENDING THE REFERENCE ETALON'S INPUT/OUTPUT FIBER. 


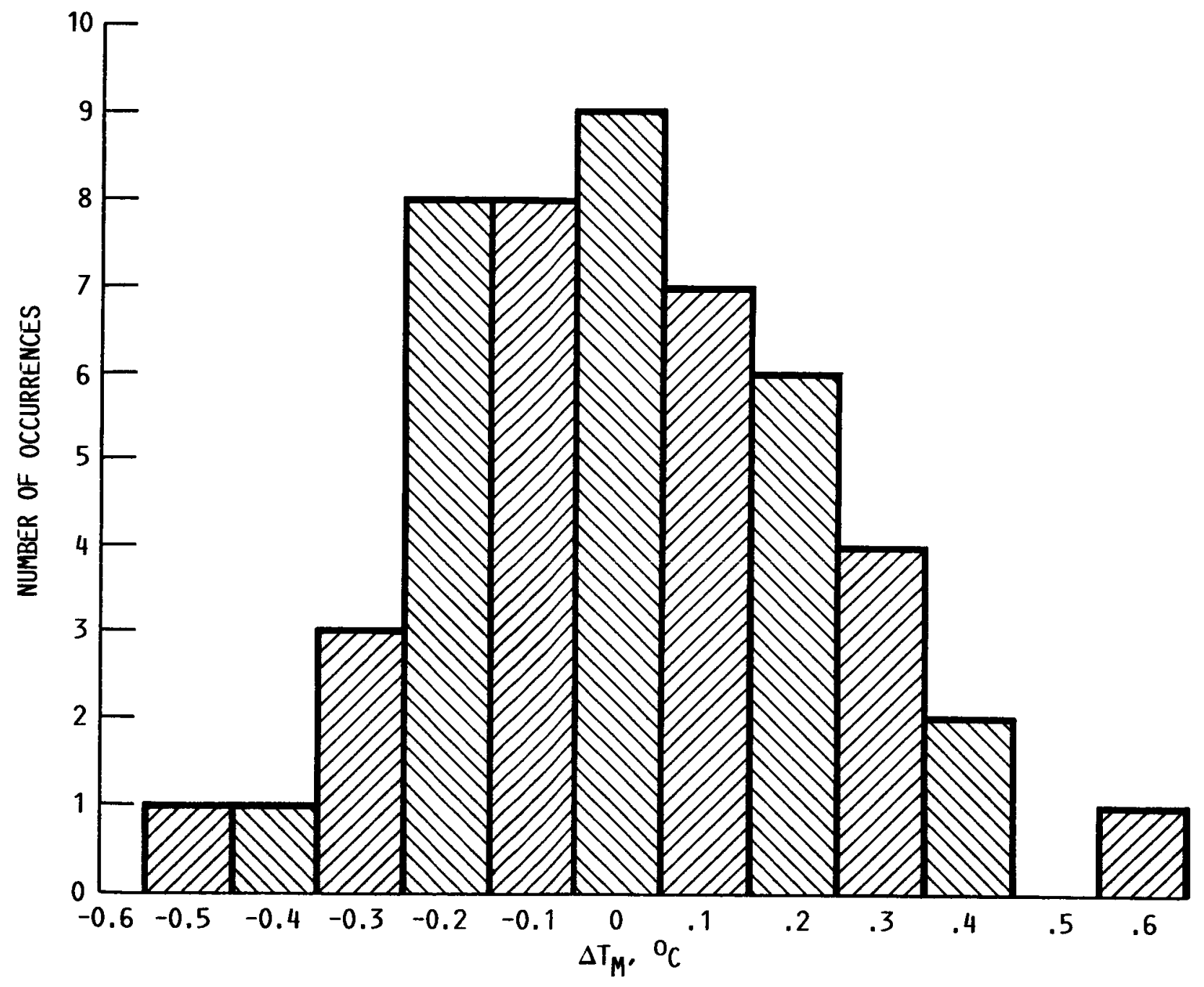

FiguRE 9. - CHANGES IN $T_{M}$ CAUSED BY RECONNECTING the SENSOR. 


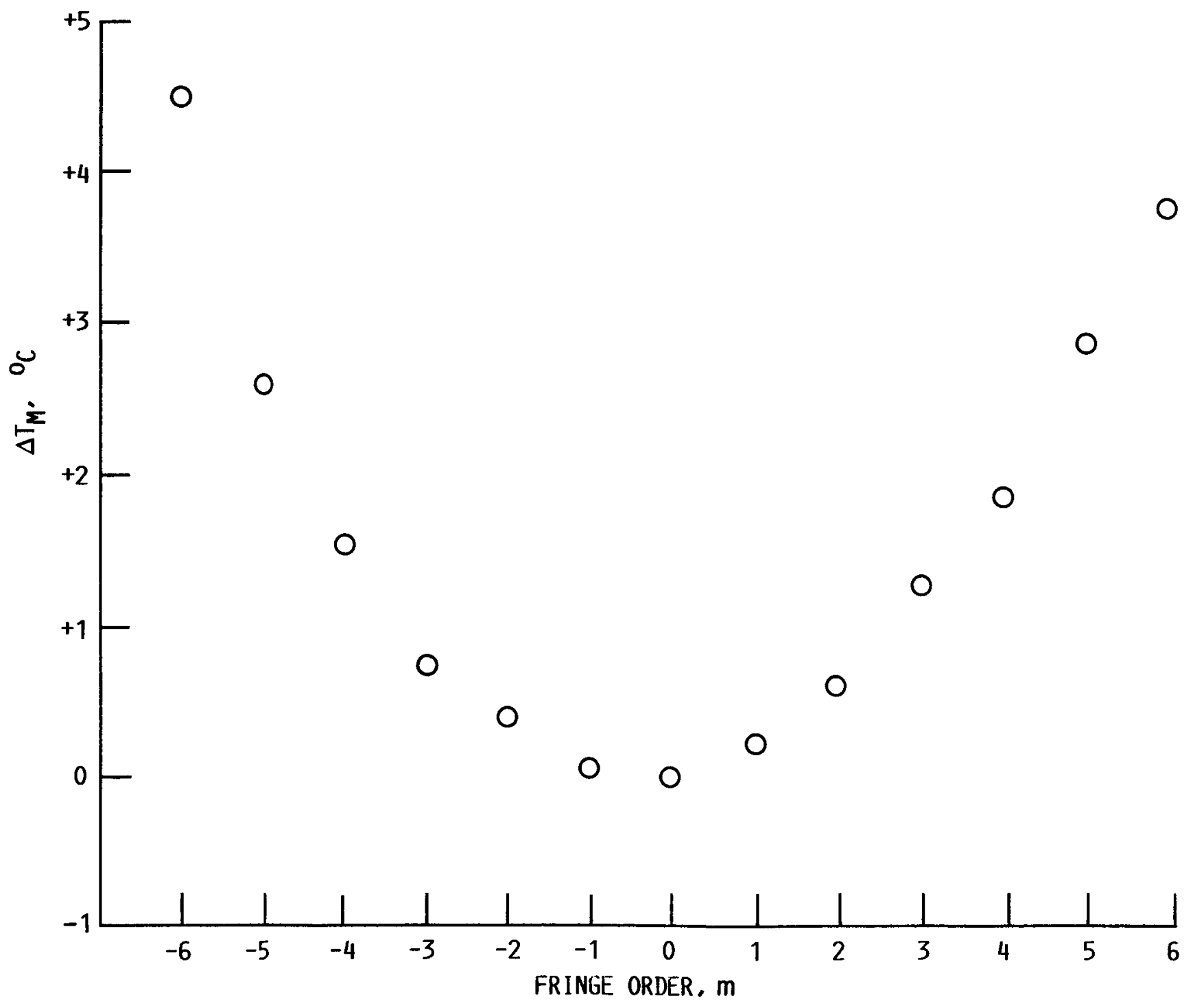

FIGURE 10. - CHANGE IN TM AS A FUNCTION OF FRINGE ORDER $\mathrm{m}$. 


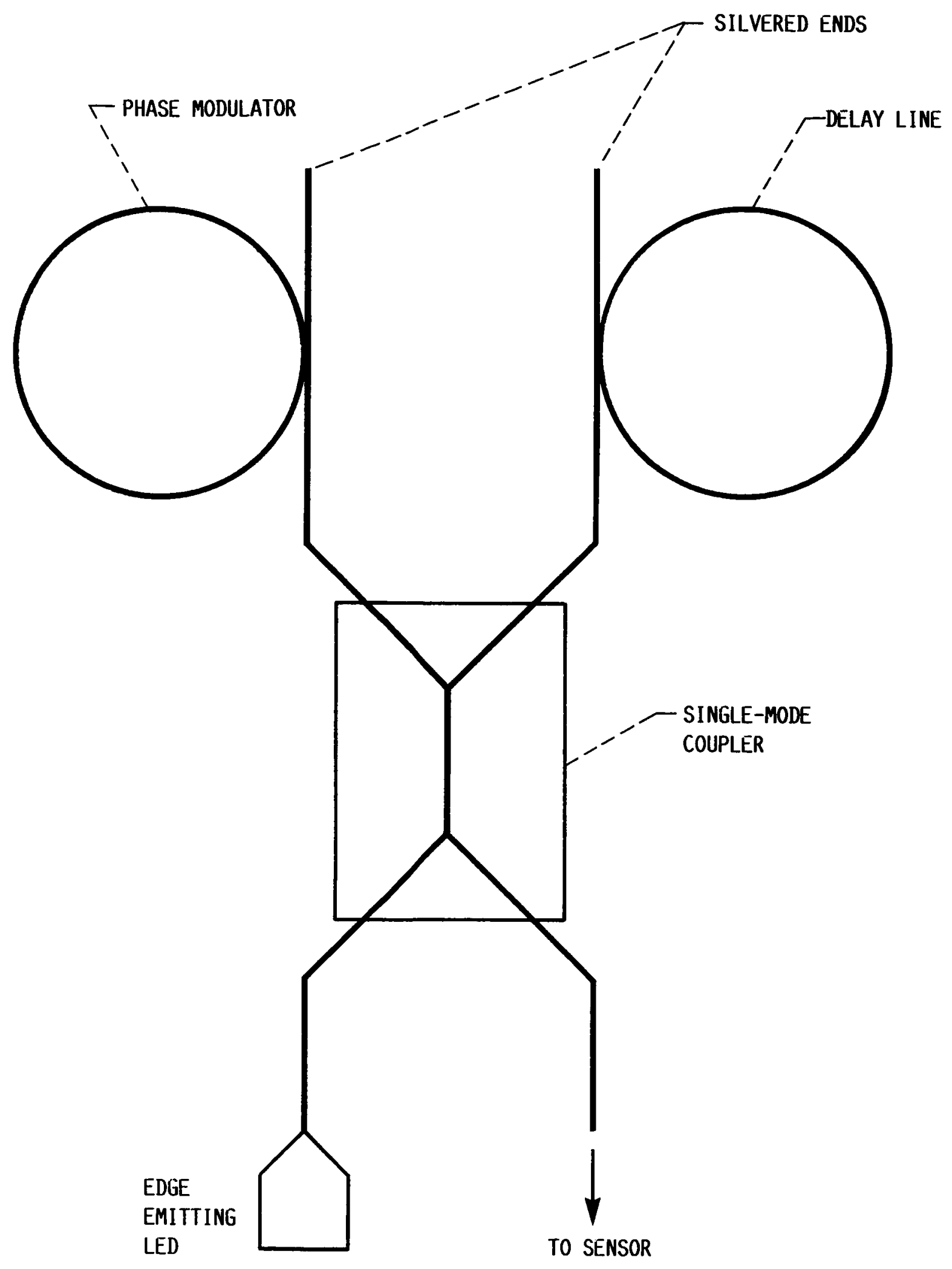

FIGURE 11. - ALL-SINGLE-MODE-FIBER ANALYZER INTERFEROMETER. 


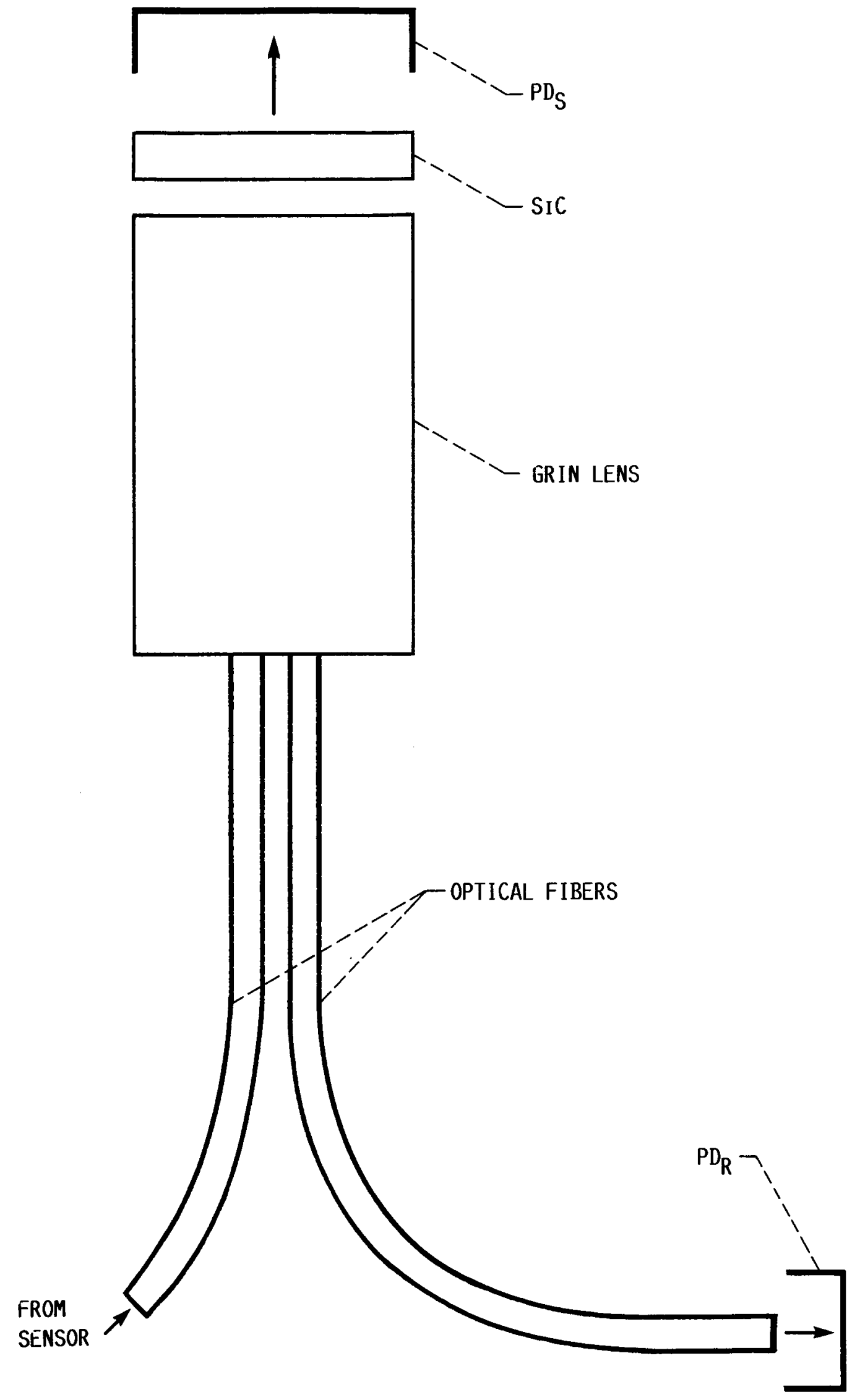

FIGURE 12. - PASSIVE SIC-ETALON ANALYZER. 


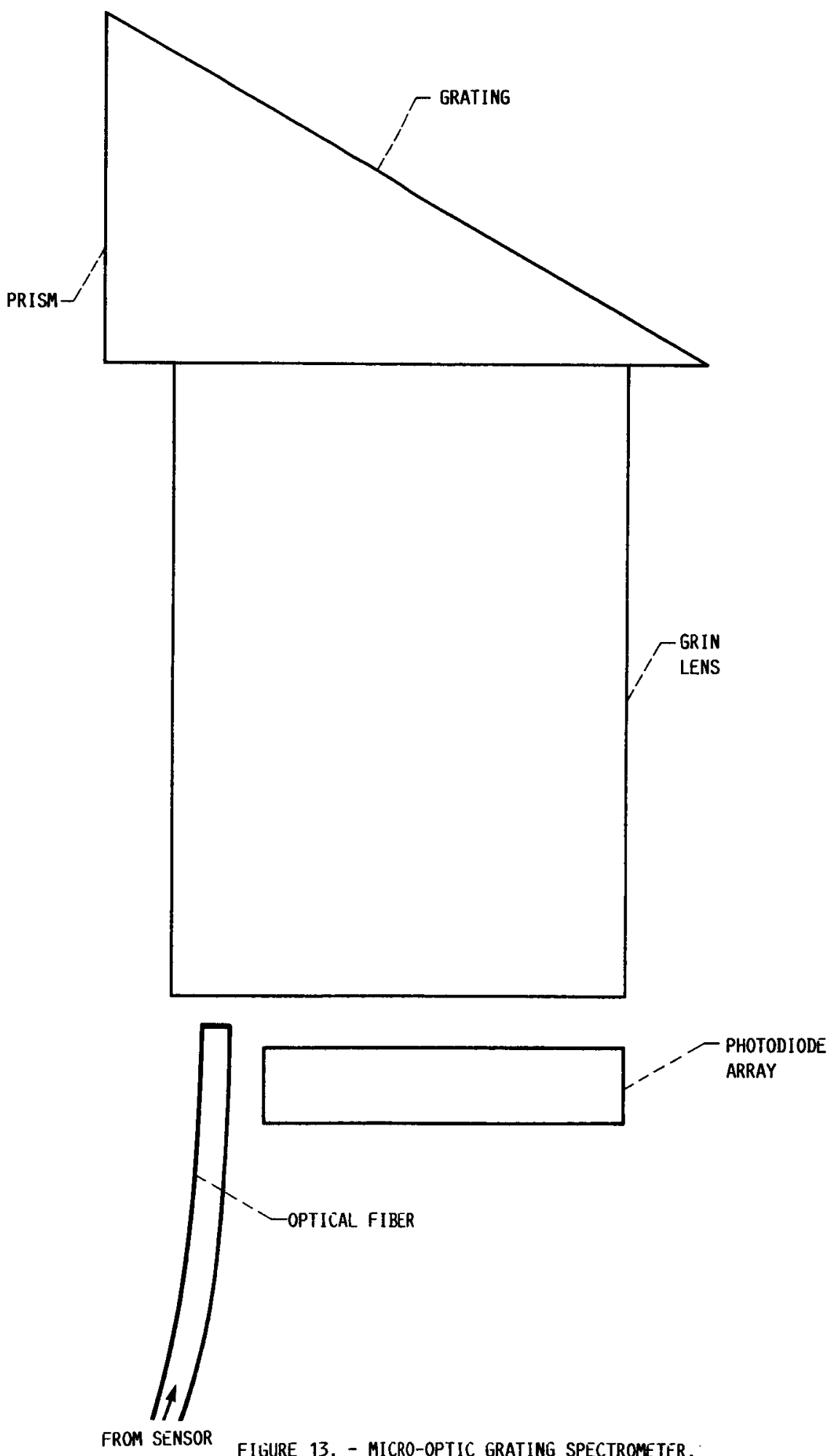

FROM SENSOR FIGURE 13. - MICRO-OPTIC GRATING SPECTROMETER. 


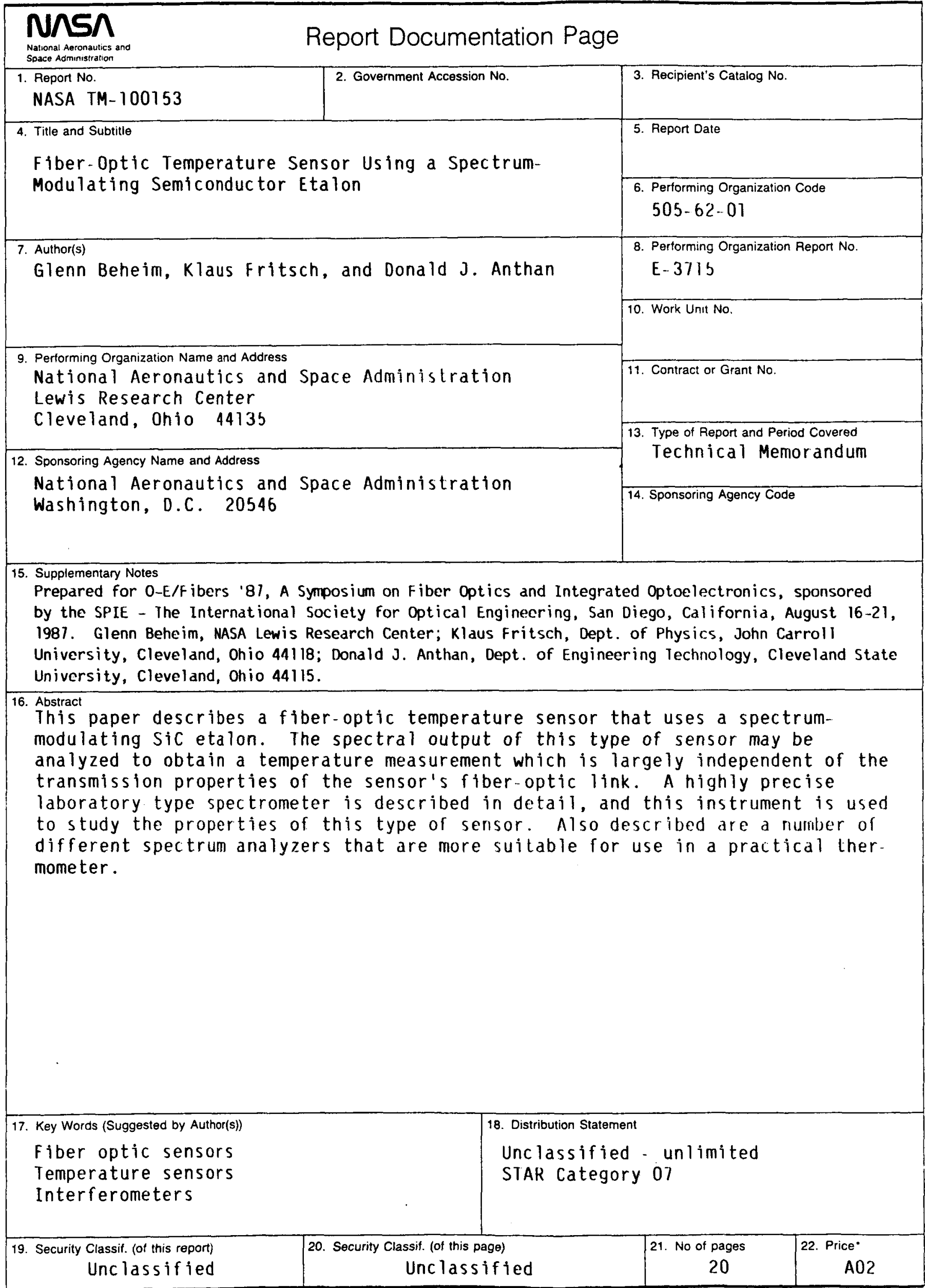

NASA FOAM 1626 OCT $86 \quad$ "For sale by the National Technical Information Service, Springfield, Virginia 22161 